\title{
Clinical Importance of Morphological Multilineage Dysplasia in Acute Myeloid Leukemia with Myelodysplasia Related Changes
}

\author{
Sang Hyuk Park, M.D., Hyun-Sook Chi, M.D., Seo-Jin Park, M.D., Seongsoo Jang, M.D., and Chan-Jeoung Park, M.D. \\ Department of Laboratory Medicine, University of Ulsan College of Medicine and Asan Medical Center, Seoul, Korea
}

\begin{abstract}
Background : AML with myelodysplasia related changes (AML MRC) is known to show a poor prognosis compared with de novo AML, but controversies exist about the prognostic impact of multilineage dysplasia (MLD) among MRC. We investigated the prognostic impact of MLD in AML MRC.

Methods : A total of 357 patients newly diagnosed as AML at Asan Medical Center from January 2001 to December 2005 were analyzed. They were diagnosed and classified as AML with recurrent genetic abnormalities, AML MRC, and AML not otherwise specified (AML NOS). Prognostic markers including overall survival (OS) and event free survival (EFS) were obtained through retrospective analysis of electronic medical records.

Results : AML MRC patients showed a lower complete remission (CR) rate (44.7\% vs. $64.9 \%, P=$ 0.002 ) and shorter OS (297 vs. 561 days, $P=0.004$ ) and EFS ( 229 vs. 374 days, $P=0.004$ ) than AML NOS patients. Patients with MLD among AML MRC also showed a lower CR rate $(37.7 \%, P=0.001)$ and shorter OS (351 days, $P=0.036$ ) and EFS (242 days, $P=0.076$ ) than AML NOS patients. However, among AML MRC patients, there were no differences in OS, EFS and CR between patients with and without MLD.

Conclusions : AML MRC patients showed a lower CR rate and shorter OS and EFS than AML NOS patients. AML MRC patients with MLD showed similar results and their prognosis was not different from those without MLD. MLD findings among AML MRC could be an independent poor prognostic factor in de novo AML. (Korean J Lab Med 2010;30:231-8)
\end{abstract}

Key Words : Prognosis, Multilineage, Dysplasia, AML, Myelodysplasia, Related, Changes

\section{서 론}

골수이형성관련 급성골수성백혈병(AML with myelodysplasia related changes, AML MRC)은 골수이형성증후군(MDS) 의 병력 또는 $\mathrm{MDS}$ 관련 세포유전학적 이상 또는 2 가지 이상의 계열에서 $50 \%$ 이상의 이형성이 관찰되는 형태학적 다계열이형 성(multilineage dysplasia, MLD)이 있는 환자에서 말초혈액 또는 골수천자의 모세포분율이 $20 \%$ 를 넘고 세포독성 치료의 병 력이나 AML 관련 반복염색체이상(AML with recurrent genet-

Received: November 9, 2009

Manuscript No : KJLM09-131

Revision received: March 23, 2010

Accepted : April 30, 2010

Corresponding author : Hyun-Sook Chi, M.D. Department of Laboratory Medicine, Asan Medical Center and University of Ulsan College of Medicine, 388-1 Pungnap 2-dong, Songpa-gu, Seoul 138-736, Korea

Tel : +82-2-3010-4502, Fax : +82-2-478-0884

E-mail : hschi@amc.seoul.kr

ISSN 1598-6535 (C) The Korean Society for Laboratory Medicine ic abnormalities, AML RGA)이 없을 때 진단하게 된다. AML RGA에는 t(8;21)(q22;q22), inv(16)(p13.1q22)/t(16;16)(p13.1; q22), t(15;17)(q22;q12), t(9;11)(p22;q23), t(6;9)(p23;q34), inv(3)(q21q26.2)/t(3;3)(q21;q26.2), t(1;22)(p13;q13) 등이 속 하며 $\mathrm{MDS}$ 관련 세포유전학적 이상에는 $\mathrm{AML} \mathrm{RGA}$ 에 해당하 지 않는 염색체이상이 3 개를 초과하여 존재할 경우이거나 또는 $5,7,9,11,13$ 번 염색체의 장완 결실 또는 12 번 염색체의 단완 결 실 및 여러 가지의 균형 전좌(balanced translocation)가 속한 다[1]. AML MRC는 심한 전혈구감소증을 잘 보이며 고령의 환 자에서 흔하고 $\mathrm{CD} 7, \mathrm{CD} 56$ 이상표현이 흔하다고 알려져 있으며 완전관해율이 다른 AML에 비해 낮고 고위험군 핵형이상이 잘 동반되어 예후가 좋지 않다고 알려져 있다[1, 2]. MLD를 동반 한 $\mathrm{AML} \mathrm{MRC}$ 의 경우에도 일반적으로는 좋지 않은 예후를 보이 지만 고위험군 핵형이상의 역할을 배제한 MLD의 독립적인 예 후인자로써의 역할에 대해서는 논란이 있어 왔다. 이에 저자들 은 단일기관에서 새로이 진단된 357 명의 $\mathrm{AML}$ 환자를 대상으 
로 $\mathrm{AML} \mathrm{MRC}$ 환자에서 $\mathrm{MLD}$ 의 임상적 의의에 대해 분석하고 자 하였다.

\section{대상 및 방법}

\section{1. 대상 환자 및 분류, 치료 방법}

2001년 1월부터 2005년 12월까지 울산의대 서울아산병원에 서 AML로 처음 진단받은 357 명의 환자들을 대상으로 하였다. 모든 환자들은 2008 년 개정된 $\mathrm{WHO}$ 분류에 의해 $\mathrm{AML} \mathrm{RGA}$, AML MRC, 미분류 AML (AML not otherwise specified, AML NOS)로 분류하였으며[1] AML M3 (French American British, $\mathrm{FAB}$ 분류)를 제외한 환자들은 진단 후 cytarabine 100-200 $\mathrm{mg} / \mathrm{m}^{2}$ 씩 제 1 일부터 7일간 계속 정주하고 idarubicin $12 \mathrm{mg} / \mathrm{m}^{2}$ 을 제 1 일부터 3 일간 매일 정주하는 1 차 관해유도치료를 받았고 치료 시작 14 일째 시행한 골수검사에서 모세포분율이 $5 \%$ 를 넘 는 경우 동일 용량으로 cytarabine은 5일, idarubicin은 2 일간 투여하는 2 차 관해유도치료를 받았다. 완전관해는 골수의 세포 밀도가 $25 \%$ 이상을 나타내고 모세포분율이 $5 \%$ 미만인 경우로 하였고 완전관해에 도달한 환자들은 cytarabine과 anthracycline으로 이루어진 3회의 공고요법을 시행 받았다. AML M3 환자들은 all-transretinoic acid에 기초한 항암요법을 시행 받 았으며 HLA가 일치하는 공여자가 있는 젊은 환자의 경우에는 1 차 완전관해 상태에서 골수이식을 시행 받았다.

\section{2. 전체 환자 및 $\mathrm{AML} \mathrm{MRC} \mathrm{환자의} \mathrm{임상적} \mathrm{특성} \mathrm{및} \mathrm{예후}$}

모든 환자들의 성별, 연령, $\mathrm{FAB}$ 분류, 진단 시 총 혈구 수, 모 세포분율, 유세포검사 결과, 세포유전학적 이상 유무, FLT3 ITD (Fms-related tyrosine kinase 3 internal tandem duplications), FLT3 D835 돌연변이 유무, 추적검사 중 완전관해, 재 발 및 사망 유무에 대해 의무기록을 후향적으로 참고하여 조사 하였다. 예후 분석을 위해 전체생존기간 및 무질병생존기간을 구하였고 언급된 변수들에 대해 AML MRC 환자와 AML NOS 환자 및 $\mathrm{AML}$ RGA 환자의 비교를 시행하였다.

\section{3. $\mathrm{AML} M \mathrm{MRC}$ 환자의 소분류별 예후 비교}

$\mathrm{AML} \mathrm{MRC}$ 환자를 이전 $\mathrm{MDS}$ 병력이 있는 경우, $\mathrm{MDS}$ 연관 세포유전학적 이상의 존재, $\mathrm{MLD}$ 를 동반한 경우로 나누어 각 군 간의 완전관해율, 사망률, 전체생존기간 및 무질병생존기간을
비교하였다. MLD는 2008년 $\mathrm{WHO}$ 분류에 따라 적어도 2 개 이 상의 계열에서 $50 \%$ 이상의 이형성이 관찰되는 경우로 정의하였 으며[1] 추가적으로 $\mathrm{MLD}$ 를 동반한 $\mathrm{AML} \mathrm{MRC} \mathrm{환자와} \mathrm{MLD}$ 를 동반하지 않은 $\mathrm{AML} \mathrm{MRC} \mathrm{환자에} \mathrm{대해} \mathrm{같은} \mathrm{비교를} \mathrm{시행하였다.}$

\section{4. $\mathrm{AML} M \mathrm{MRC}$ 또는 $\mathrm{MLD}$ 를 동반한 $\mathrm{AML} \mathrm{MRC}$ 환자와 이외의 환자와의 예후 비교}

$\mathrm{MRC}$ 및 $\mathrm{MLD}$ 가 예후에 미치는 영향을 분석하기 위해 $\mathrm{AML}$ $\mathrm{MRC}$ 환자 또는 $\mathrm{MLD}$ 를 동반한 $\mathrm{AML} \mathrm{MRC}$ 환자와 이외의 환자 로 나누어 각 군 간의 완전관해율, 사망률, 전체생존기간 및 무 질병생존기간을 비교하였다. 추가적으로 이외의 환자 중 $\mathrm{t}(8 ; 21)$ (q22;q22), inv(16)(p13.1q22)/t(16;16)(p13.1;q22), t(15;17)(q22; q12) 등의 좋은 예후를 보이는 세포유전학적 이상을 보이는 환 자를 제외한 후 같은 비교를 시행하였다.

\section{5. 여러 변수의 예후에 미치는 영향에 대한 다변량분석}

전체생존기간, 무질병생존기간, 완전관해율, 재발률에 미치는 여러 변수의 영향을 분석하기 위해 연령, 백혈구 수, 모세포분율, 세포유전학적 이상, $\mathrm{MRC}$ 및 $\mathrm{MLD}$ 의 존재, FLT3 돌연변이 등 의 변수에 대한 다변량분석을 시행하였다.

\section{6. 통계 처리}

성별, 완전관해율, 재발률, 사망률, FLT3 돌연변이 여부의 비 교에는 Chi square test를 시행하였고 연령, 총 혈구 수, 모세포 분율의 비교에는 Student t test를 시행하였다. 전체생존기간 및 무질병생존기간의 비교에는 Kaplan-Meier 및 log-rank test를 시행하였다. 예후에 미치는 변수에 대한 다변량분석에는 이분형 로지스틱 분석 및 Cox's proportional hazard model 을 사용하여 상대위험도(hazard ratio)를 구하였다. 모든 분석 에서는 양측검정을 시행하여 $P$ 값을 얻었고 $P$ 값이 0.05 미만일 때 통계적으로 유의하다고 판정하였다.

\section{결 과}

\section{1. 전체 환자 및 $\mathrm{AML} M R C$ 환자의 임상적 특성 및 예후}

전체 357명의 환자 중 AML RGA, AML MRC, AML NOS는 각각 115 명(32.2\%), 94명(26.3\%), 148명(41.5\%)이었다. $\mathrm{AML}$ 
$\mathrm{MRC}$ 환자가 $\mathrm{AML} \mathrm{NOS}$ 환자에 비해 헤모글로빈이 낮은 경향 을 보였고(8.5 g/dL vs. $9.0 \mathrm{~g} / \mathrm{dL}, P=0.09)$ 백혈구 수(5,100/ $\mu \mathrm{L}$ vs. $10,800 / \mu \mathrm{L}, P<0.001)$ 및 모세포분율(50.5\% vs. $66.1 \%, P<$ 0.001)이 낮았으며 FLT3 ITD 돌연변이가 적었고(5.1\% vs. $17.4 \%$, $P=0.011)$ 완전관해율이 낮았으며(44.7\% vs. $64.9 \%, P=0.002)$, 사망률이 높은 경향을 보였다(76.6\% vs. $64.9 \%, P=0.054)$. 전 체생존기간 및 무질병생존기간의 비교에서 $\mathrm{AML} \mathrm{MRC} \mathrm{환자가}$ $\mathrm{AML} \mathrm{NOS}$ 환자에 비해 전체생존기간(297일 vs. 561일, $P=$ 0.004 ) 및 무질병생존기간(229일 vs. 374일, $P=0.004)$ 이 짧았 고 $\mathrm{AML} \mathrm{RGA}$ 환자와의 비교에서도 같은 결과를 보였다 $(P<$ 0.001) (Fig. 1, Table 1).

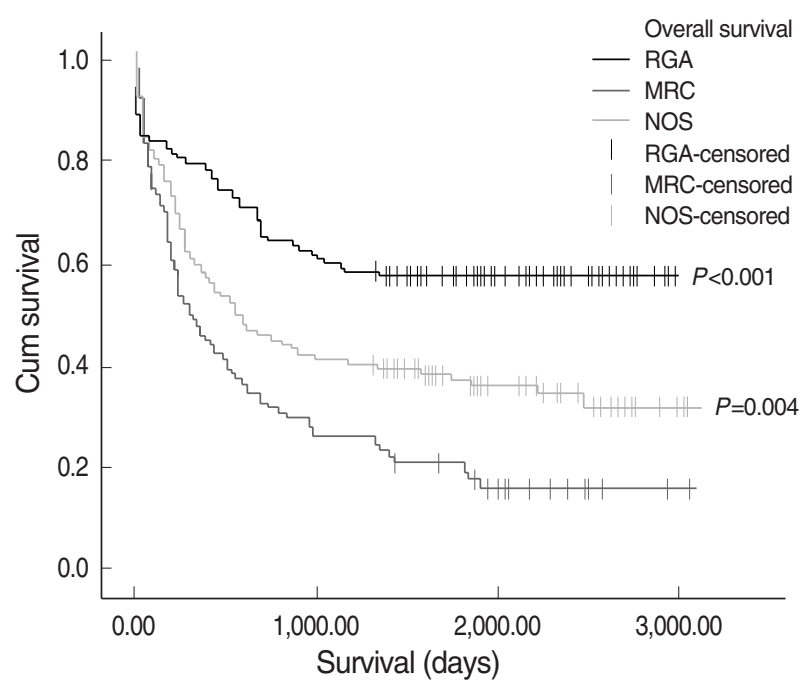

\section{2. $\mathrm{AML} M R C$ 환자군의 소분류별 예후 비교}

전체 94 명의 $\mathrm{AML} \mathrm{MRC}$ 환자 중 이전 $\mathrm{MDS}$ 병력을 보인 환 자가 9 명(9.6\%), $\mathrm{MDS}$ 연관 세포유전학적 이상을 보인 환자가 32 명(34.0\%), MLD를 동반한 환자가 53명(56.4\%)이었다. 전체 생존기간 및 무질병생존기간은 세 군 모두 유의한 차이가 없었 다(Fig. 2). $\mathrm{MLD}$ 를 동반한 환자에서 $\mathrm{MDS}$ 연관 세포유전학적 이상을 보인 환자보다 완전관해율이 낮은 경향을 보였으며(37.7\% VS. $59.4 \%, P=0.052)$ 이전 $\mathrm{MDS}$ 병력을 보인 환자보다 사망률 이 높았다(81.1\% vs. 22.2\%, P<0.001) (Table 2). 그러나 MLD 를 동반한 $\mathrm{AML} \mathrm{MRC} \mathrm{환자와} \mathrm{MLD}$ 를 동반하지 않은 $\mathrm{AML} \mathrm{MRC}$

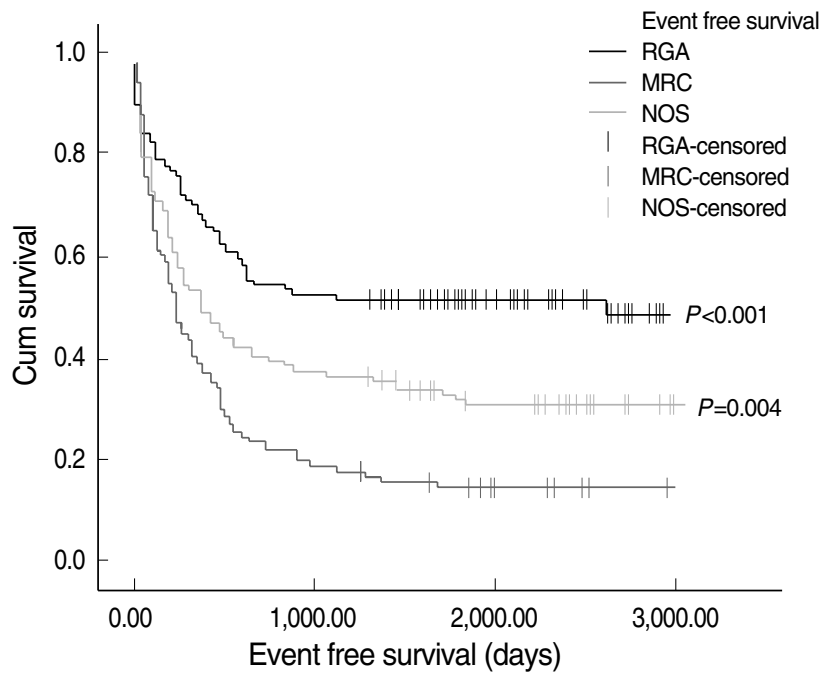

Fig. 1. Comparison of overall survival and event free survival in 357 patients among $3 \mathrm{AML}$ groups according to revised $2008 \mathrm{WHO}$ classification.

Abbreviations: RGA, recurrent genetic abnormalities; MRC, myelodysplasia related changes; NOS, not otherwise specified.

Table 1. Clinical characteristics and prognosis in 3 AML groups

\begin{tabular}{|c|c|c|c|c|}
\hline Clinical variables & AML RGA $(N=115)$ & AML NOS (N=148) & AML MRC (N=94) & $P$ value* \\
\hline Age, median (range) & $42(2-80)$ & $45(1-82)$ & $53(2-79)$ & 0.362 \\
\hline $\mathrm{Hb}(\mathrm{g} / \mathrm{dL})$, median (range) & $8.8(2.6-14.7)$ & $9.0(3.6-15.1)$ & $8.5(3.2-11.6)$ & 0.09 \\
\hline 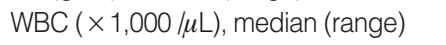 & $8.4(0.4-239.4)$ & $10.8(0.7-333.4)$ & $5.1(0.3-246.0)$ & $<0.001$ \\
\hline Platelet ( $\times 1,000 / \mu \mathrm{L})$, median (range) & $44.0(5.0-511.0)$ & $57.0(2.9-302.0)$ & $42.5(6.0-433.0)$ & 0.992 \\
\hline Blast (\%), median (range) & $66.8(20.2-96.2)$ & $66.1(5.2-98.8)$ & $50.5(16.4-96.2)$ & $<0.001$ \\
\hline FLT3 ITD mutation & $100.0 \%$ & $17.4 \%$ & $5.1 \%$ & 0.011 \\
\hline FLT3D835 mutation & $14.7 \%$ & $7.6 \%$ & $5.0 \%$ & 0.605 \\
\hline $\mathrm{CR}$ & $79.1 \%$ & $64.9 \%$ & $44.7 \%$ & 0.002 \\
\hline Relapse & $26.1 \%$ & $30.4 \%$ & $29.8 \%$ & 0.919 \\
\hline Death & $26.1 \%$ & $64.9 \%$ & $76.6 \%$ & 0.054 \\
\hline OS (days), median & $1,455.0, P<0.001^{\dagger}$ & 561 & 297 & 0.004 \\
\hline EFS (days), median & $1,294.0, P<0.001^{\dagger}$ & 374 & 229 & 0.004 \\
\hline
\end{tabular}

${ }^{*} P$ value, NOS compared with MRC; ${ }^{\dagger} P$ value compared with MRC.

Abbreviations: RGA, recurrent genetic abnormalities; NOS, not otherwise specified; MRC, myelodysplasia related changes; WBC, white blood cells; FLT3, Fms-related tyrosine kinase 3; ITD, internal tandem duplication; CR, complete remission; OS, overall survival; EFS, event free survival. 

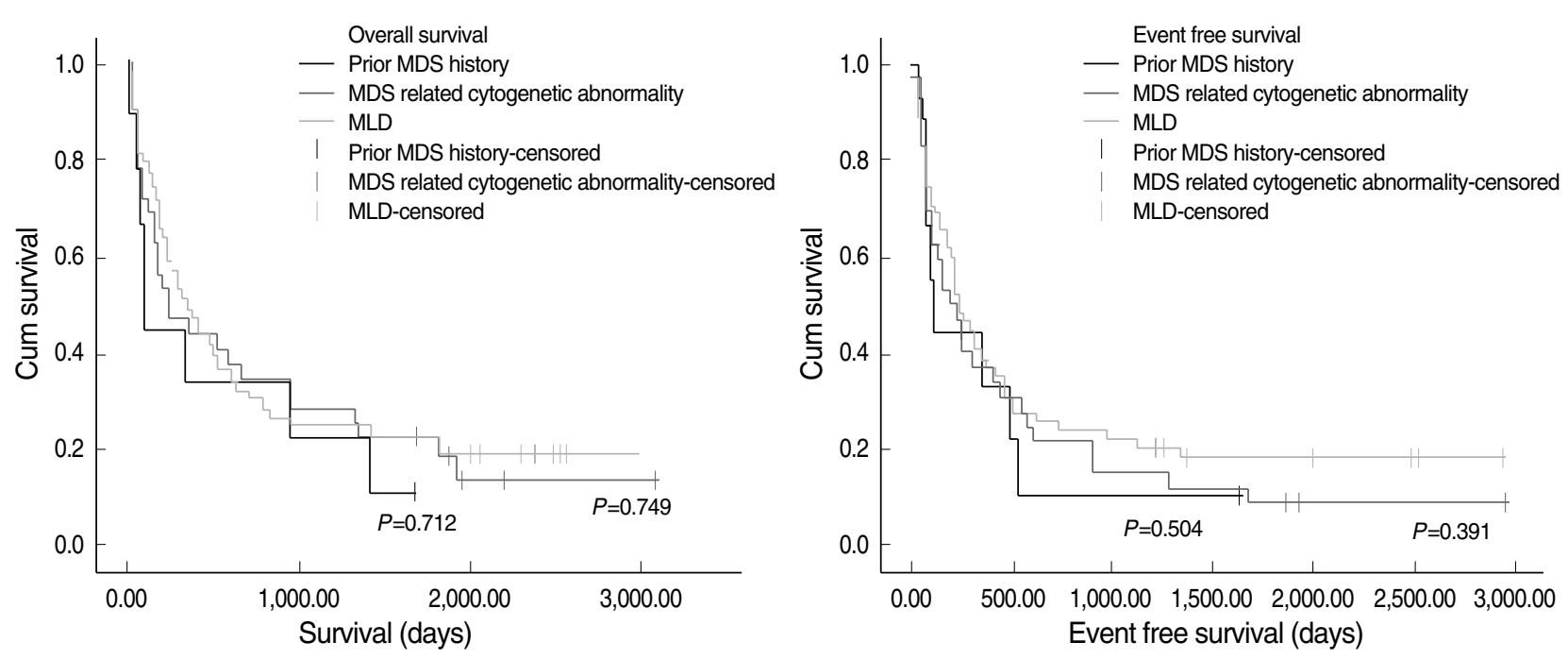

Fig. 2. Comparison of overall survival and event free survival of AML MRC patients among 3 subgroups.

Abbreviation: MLD, multilineage dysplasia.

Table 2. Comparison of OS, EFS, CR and death rate among subgroups of AML MRC

\begin{tabular}{|c|c|c|c|c|}
\hline \multirow{2}{*}{ Type and description } & \multicolumn{2}{|c|}{ Median (days) } & \multirow{2}{*}{$\mathrm{CR}$} & \multirow{2}{*}{ Death } \\
\hline & OS & EFS & & \\
\hline $\begin{array}{l}\text { Prior MDS history }(\mathrm{N}=9) \\
(P \text { value compared with MLD) }\end{array}$ & $\begin{array}{c}113.0 \\
P=0.712\end{array}$ & $\begin{array}{c}97.0 \\
P=0.504\end{array}$ & $\begin{array}{c}33.3 \% \\
P=0.800\end{array}$ & $\begin{array}{l}22.2 \% \\
P<0.001\end{array}$ \\
\hline $\begin{array}{l}\text { MDS related cytogenetic abnormality }(\mathrm{N}=32) \\
(P \text { value compared with } \mathrm{MLD})\end{array}$ & $\begin{array}{c}234.0 \\
P=0.749\end{array}$ & $\begin{array}{c}184.0 \\
P=0.391\end{array}$ & $\begin{array}{c}59.4 \% \\
P=0.052\end{array}$ & $\begin{array}{c}84.3 \% \\
P=0.704\end{array}$ \\
\hline $\operatorname{MLD}(\mathrm{N}=53)$ & 351.0 & 242.0 & $37.7 \%$ & $81.1 \%$ \\
\hline
\end{tabular}

Abbreviations: OS, overall survival; EFS, event free survival; CR, complete remission; MRC, myelodysplasia related changes; MLD, multilineage dysplasia.

환자 간의 비교에서는 완전관해율, 사망률, 전체생존기간 및 무 질병생존기간 모두 유의한 차이가 없었다(Table 3).

\section{3. $\mathrm{AML} \mathrm{MRC}$ 또는 $\mathrm{MLD}$ 를 동반한 $\mathrm{AML} \mathrm{MRC}$ 환자와 이외의 환자와의 예후 비교}

$\mathrm{AML} \mathrm{MRC}$ 환자가 $\mathrm{MRC}$ 이외의 $\mathrm{AML}$ 환자에 비해 전체생존 기간(297일 vs. 994일, $P<0.001$ ) 및 무질병생존기간(229일 vs. 579일, $P<0.001)$ 이 짧았고 완전관해율(44.7\% vs. $71.1 \%, P<$ 0.001)이 낮았으며 사망률(76.6\% Vs. $47.9 \%, P<0.001)$ 도 높았 다. 또한 좋은 예후를 보이는 세포유전학적 이상을 제외한 $\mathrm{MRC}$ 이외의 AML 환자에 비해서도 전체생존기간(297일 vS. 556일, $P=0.004)$ 및 무질병생존기간(229일 vs. 373일, $P=0.007)$ 이 짧았고 완전관해율(44.7\% vs. $65.4 \%, P=0.001)$ 이 낮았으며 사 망률(76.6\% vs. $64.7 \%, P=0.049)$ 이 높았다(Table 4). MLD를 동반한 $\mathrm{AML} \mathrm{MRC}$ 환자가 $\mathrm{MLD}$ 이외의 $\mathrm{AML}$ 환자에 비해 높 은 연령(56세 vs. 44세, $P=0.006)$ 및 낮은 모세포분율(42.0\%
Table 3. Comparison of OS, EFS, CR and death rate between MLD and other MRC

\begin{tabular}{|c|c|c|c|c|}
\hline & \multicolumn{2}{|c|}{ Median (days) } & \multirow{2}{*}{$\mathrm{CR}$} & \multirow{2}{*}{ Death } \\
\hline & OS & EFS & & \\
\hline $\begin{array}{l}\text { MLD } \\
\text { ( } P \text { value compared } \\
\quad \text { with other MRC) }\end{array}$ & $\begin{array}{c}351.0 \\
P=0.342\end{array}$ & $\begin{array}{c}242.0 \\
P=0.154\end{array}$ & $\begin{array}{c}37.7 \% \\
P=0.124\end{array}$ & $\begin{array}{c}81.1 \% \\
P=0.238\end{array}$ \\
\hline Other MRC & 212.0 & 162.0 & $53.7 \%$ & $70.7 \%$ \\
\hline
\end{tabular}

Abbreviations: OS, overall survival; EFS, event free survival; $\mathrm{CR}$, complete remission; MLD, multilineage dysplasia; MRC, myelodysplasia related changes.

vS. $66.3 \%, P<0.001)$ 을 보였으며 전체생존기간(351일 vS. 858 일, $P=0.002)$ 및 무질병생존기간(242일 vs. 463일, $P=0.011)$ 이 짧았고(Fig. 3) 완전관해율(37.7\% vs. $68,8 \%, P<0.001)$ 이 낮았 으며 사망률( $81.1 \%$ vs. $51.0 \%, P<0.001)$ 이 높았고 이는 $\mathrm{AML}$ $\mathrm{MRC}$ 환자와 동일한 결과였다. 좋은 예후를 보이는 세포유전학 적 이상을 제외한 $\mathrm{MLD}$ 이외의 $\mathrm{AML}$ 환자에 비해서도 완전관해 율(37.7\% Vs. $62.9 \%, P=0.001)$ 이 낮았으며 사망률(81.1\% Vs. 

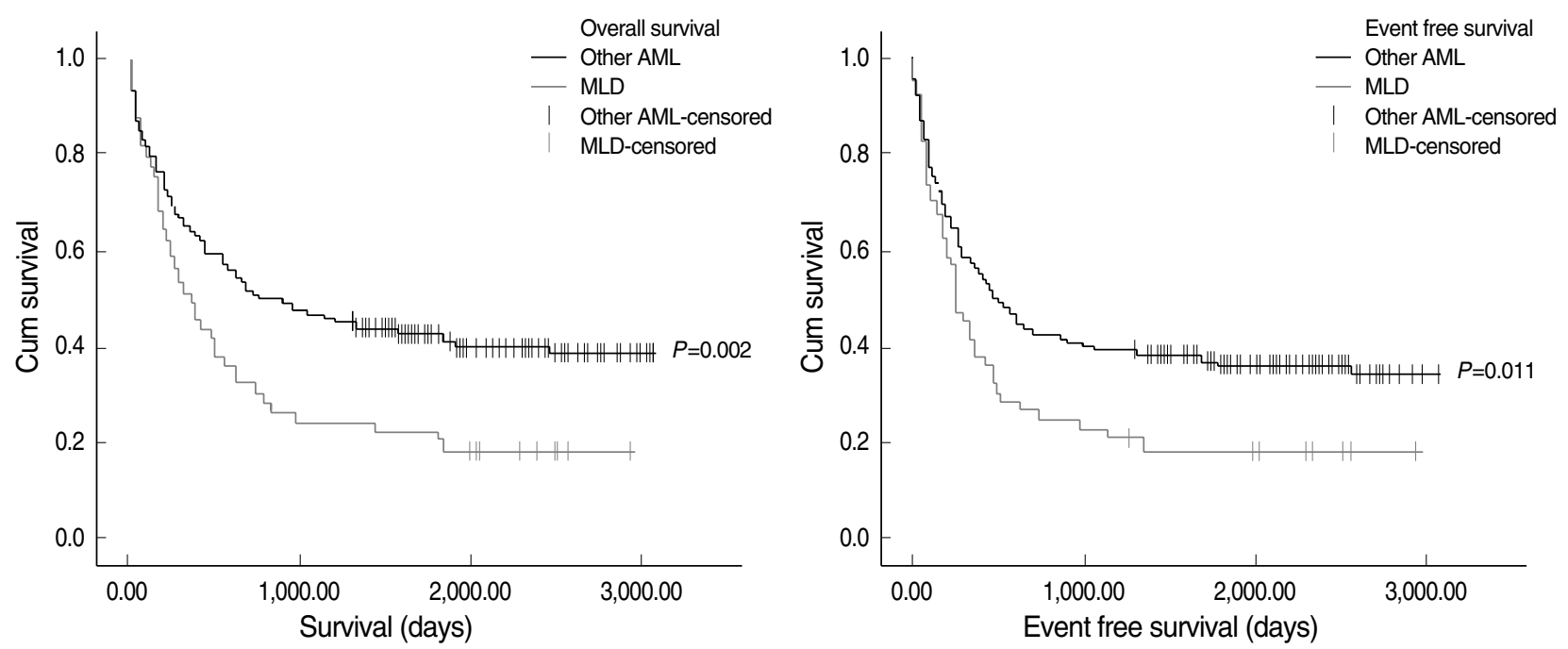

Fig. 3. Comparison of overall survival and event free survival of AML MLD patients compared with other AML. Abbreviation: MLD, multilineage dysplasia.

Table 4. Comparison of OS, EFS, CR and death rate between AML MRC and other AML

\begin{tabular}{|c|c|c|c|c|}
\hline & \multicolumn{2}{|c|}{ Median (days) } & \multirow{2}{*}{$\mathrm{CR}$} & \multirow{2}{*}{ Death } \\
\hline & OS & EFS & & \\
\hline $\begin{array}{l}\text { Other } \mathrm{AML}(\mathrm{N}=263) \\
(P \text { value compared with } \mathrm{AML} \mathrm{MRC})\end{array}$ & $\begin{array}{c}994.0 \\
P<0.001\end{array}$ & $\begin{array}{l}579.0 \\
P<0.001\end{array}$ & $\begin{array}{c}71.1 \% \\
P<0.001\end{array}$ & $\begin{array}{l}47.9 \% \\
P<0.001\end{array}$ \\
\hline $\begin{array}{l}\text { Other AML, good prognostic cytogenetics excluded }(\mathrm{N}=156) \\
(P \text { value compared with AML MRC) }\end{array}$ & $\begin{array}{c}556.0 \\
P=0.004\end{array}$ & $\begin{array}{l}373.0 \\
P=0.007\end{array}$ & $\begin{array}{c}65.4 \% \\
P=0.001\end{array}$ & $\begin{array}{l}64.7 \% \\
P=0.049\end{array}$ \\
\hline AML MRC (N=94) & 297.0 & 229.0 & $44.7 \%$ & $76.6 \%$ \\
\hline
\end{tabular}

Abbreviations: OS, overall survival; EFS, event free survival; CR, complete remission; MRC, myelodysplasia related changes.

Table 5. Comparison of OS, EFS, CR and death rate between AML MLD and other AML

\begin{tabular}{lcccc}
\hline \multirow{2}{*}{ Type and description } & \multicolumn{2}{c}{ Median (days) } & & CR \\
\cline { 2 - 3 } & OS & EFS & & \\
\hline Other AML $(\mathrm{N}=304)$ & 858.0 & 463.0 & $68.8 \%$ & $51.0 \%$ \\
$\quad(P$ value compared with MLD) & $P=0.002$ & $P=0.011$ & $P<0.001$ & $P<0.001$ \\
Other AML, good prognostic cytogenetics excluded $(\mathrm{N}=197)$ & 517.0 & 309.0 & $62.9 \%$ & $66.0 \%$ \\
$\quad(P$ value compared with MLD) & $P=0.125$ & $P=0.274$ & $P=0.001$ & $P=0.034$ \\
AML NOS (N=148) & 561.0 & 374.0 & $64.9 \%$ & $64.9 \%$ \\
$(P$ value compared with MLD) & $P=0.036$ & $P=0.076$ & $P=0.001$ & $P=0.028$ \\
MLD (N=53) & 351.0 & 242.0 & $37.7 \%$ & $81.1 \%$ \\
\hline
\end{tabular}

Abbreviations: OS, overall survival; EFS, event free survival; CR, complete remission; MLD, multilineage dysplasia.

$66.0 \%, P=0.034)$ 이 높았으나 전체생존기간(351일 vs. 517일, $P=0.125)$ 및 무질병생존기간(242일 vs. 309일, $P=0.274)$ 은 유 의한 차이가 없었다. AML NOS 환자에 비해서도 전체생존기 간(351일 vs. 561일, $P=0.036)$ 이 짧았고 무질병생존기간(242일 vs. 374 일, $P=0.076)$ 도 짧은 경향을 보였으며 완전관해율(37.7\% vs. $64.9 \%, P=0.001)$ 이 낮았고 사망률( $81.1 \%$ vs. $64.9 \%, P=$
0.028)은 높았다(Table 5).

\section{4. 여러 변수의 예후에 미치는 영향에 대한 다변량분석}

60 세 이상인 경우 전체생존기간 및 무질병생존기간, 완전관해 율의 나쁜 예후인자였으며, 모세포분율이 $60 \%$ 이하인 경우 무질 
Table 6. Factors associated with OS, EFS, CR and relapse rate

\begin{tabular}{|c|c|c|c|c|c|c|c|c|c|c|c|c|}
\hline \multirow[b]{2}{*}{ Variables } & \multicolumn{3}{|c|}{ OS } & \multicolumn{3}{|c|}{ EFS } & \multicolumn{3}{|c|}{ CR } & \multicolumn{3}{|c|}{ Relapse } \\
\hline & $\begin{array}{c}\mathrm{HR} \\
(95 \% \mathrm{Cl})\end{array}$ & $\begin{array}{c}P \\
\text { value }\end{array}$ & $\begin{array}{c}\text { Adverse } \\
\text { effect }\end{array}$ & $\begin{array}{c}\mathrm{HR} \\
(95 \% \mathrm{Cl})\end{array}$ & $\begin{array}{c}P \\
\text { value }\end{array}$ & $\begin{array}{c}\text { Adverse } \\
\text { effect }\end{array}$ & $\begin{array}{c}\mathrm{HR} \\
(95 \% \mathrm{Cl})\end{array}$ & $\begin{array}{c}P \\
\text { value }\end{array}$ & $\begin{array}{c}\text { Adverse } \\
\text { effect }\end{array}$ & $\begin{array}{c}\mathrm{HR} \\
(95 \% \mathrm{Cl})\end{array}$ & $\begin{array}{c}P \\
\text { value }\end{array}$ & $\begin{array}{c}\text { Adverse } \\
\text { effect }\end{array}$ \\
\hline $\begin{array}{l}\text { Age } \\
(\leq 60 \text { vs. }>60)\end{array}$ & $\begin{array}{c}2.49 \\
(1.42-4.36)\end{array}$ & 0.001 & $>60$ & $\begin{array}{c}2.80 \\
(1.67-4.70)\end{array}$ & $<0.001$ & $>60$ & $\begin{array}{c}0.20 \\
(0.06-0.61)\end{array}$ & 0.004 & $>60$ & $\begin{array}{c}2.02 \\
(0.70-5.82)\end{array}$ & 0.192 & - \\
\hline $\begin{array}{c}\text { WBC }(\leq 20,000 / \mu \mathrm{L} \\
\text { vs. }>20,000 / \mu \mathrm{L})\end{array}$ & $\begin{array}{c}1.31 \\
(0.78-2.20)\end{array}$ & 0.308 & - & $\begin{array}{c}1.10 \\
(0.67-1.80)\end{array}$ & 0.706 & - & $\begin{array}{c}0.61 \\
(0.22-1.67)\end{array}$ & 0.336 & - & $\begin{array}{c}0.38 \\
(0.13-1.10)\end{array}$ & 0.072 & $\begin{array}{c}\leq 20,000 \\
/ \mu L\end{array}$ \\
\hline $\begin{array}{l}\text { Blasts } \\
\qquad(\leq 60 \% \text { vs. }>60 \%)\end{array}$ & $\begin{array}{c}0.74 \\
(0.46-1.20)\end{array}$ & 0.213 & - & $\begin{array}{c}0.58 \\
(0.37-0.91)\end{array}$ & 0.019 & $\leq 60 \%$ & $\begin{array}{c}1.17 \\
(0.45-3.01)\end{array}$ & 0.748 & - & $\begin{array}{c}0.57 \\
(0.23-1.42)\end{array}$ & 0.228 & - \\
\hline MRC (Yes vs. No) & $\begin{array}{c}1.95 \\
(1.10-3.46)\end{array}$ & 0.023 & Yes & $\begin{array}{c}1.86 \\
(1.08-3.20)\end{array}$ & 0.025 & Yes & $\begin{array}{c}0.28 \\
(0.09-0.88)\end{array}$ & 0.030 & Yes & $\begin{array}{c}1.47 \\
(0.51-4.23)\end{array}$ & 0.475 & - \\
\hline MLD (Yes vs. No) & $\begin{array}{c}1.87 \\
(1.33-2.64)\end{array}$ & $<0.001$ & Yes & $\begin{array}{c}1.69 \\
(1.20-2.38)\end{array}$ & 0.002 & Yes & $\begin{array}{c}0.25 \\
(0.13-0.46)\end{array}$ & $<0.001$ & Yes & $\begin{array}{c}0.73 \\
(0.37-1.47)\end{array}$ & 0.384 & - \\
\hline
\end{tabular}

Abbreviations: OS, overall survival; EFS, event free survival; $\mathrm{CR}$, complete remission; HR, hazard ratio; WBC, white blood cells; MRC, myelodysplasia related changes; MLD, multilineage dysplasia.

병생존기간에서 나쁜 예후인자로 확인되었다. $\mathrm{MRC}$ 의 존재가 전체생존기간 및 무질병생존기간, 완전관해율의 나쁜 예후인자 였으며 $\mathrm{MLD}$ 의 존재도 MRC와 동일한 결과를 보였다(Table 6).

\section{고 찰}

이전의 보고들을 통해 AML에서 예후에 관련된 인자에는 환 자의 연령, $\mathrm{FAB}$ 분류, 혼합성 면역표현형, 염색체 이상, 미세잔 류세포의 존재 등이 있다고 알려져 있었으며[3-6], 그 외 형태 학적 이형성 및 세포유전학적 이상의 임상적 의미가 구체화되면 서 2001년 WHO 분류에서 MLD를 보이고 나쁜 예후를 보인다 고 알려진 염색체이상을 동반하는 AML을 AML MLD라 명명하 였다[7]. AML MLD 환자의 경우 여러 연구에서 다른 AML에 비하여 나쁜 예후를 보인다고 알려져 왔지만 이는 나쁜 예후를 보인다고 알려진 염색체이상이 빈번한 빈도로 관찰되기 때문이 며 MLD 자체는 독립적인 예후인자가 되지 못한다는 상반된 견 해도 있었다[8-11]. 또한 삼계열이형성(trilineage dysplasia)이 관찰되는 경우에도 골수의 모세포분율이 낮고 AML M4 및 M6 의 높은 빈도를 보임과 동시에 완전관해율이 낮고 관해유지기간 및 전체생존기간이 짧아 불량한 예후를 보였다는 보고들이 있는 반면 예후와 무관하였다는 보고들도 있어 MLD의 존재가 예후 에 미치는 영향에 대해 논란이 있었다[12-17]. 2008년 개정된 WHO 분류에는 AML MLD에 이전의 세포독성 치료 병력 및 $\mathrm{MDS}$ 연관 세포유전학적 이상이 있는 경우를 포함하여 $\mathrm{AML}$ $\mathrm{MRC}$ 로 재분류하였고[1] 최근 100 명의 $\mathrm{AML}$ 환자를 대상으로 한 $\mathrm{AML} \mathrm{MRC}$ 환자의 임상적 특성에 대한 연구가 발표되었는 데 이에 따르면 AML NOS 환자에 비해 높은 발병연령 및 헤모
글로빈 수치가 낮고 전체생존기간 및 무진행생존기간이 짧았으 며 낮은 완전관해율을 보여 예후가 나빴고 MLD만을 동반한 $\mathrm{AML} \mathrm{MRC}$ 환자에서도 비슷한 결과를 보여 MRC 및 $\mathrm{MLD}$ 의 존재가 나쁜 예후와 관련이 있다고 보고하였다[18].

본 연구에서 $\mathrm{AML} \mathrm{MRC는} 26.3 \%$ 의 환자에서 발견되었고 이 는 AML MLD의 빈도를 24-38\%로 보고한 이전 결과와 유사하 였으나 최근 보고된 $\mathrm{AML} \mathrm{MRC}$ 의 빈도인 48\%보다는 낮았다[10, 18-20]. AML MRC 환자에서 AML NOS 환자에 비해 낮은 모 세포분율 및 백혈구 수를 보였는데 삼계열이형성을 동반한 AML 환자에서 그렇지 않은 환자에 비해 유의하게 낮은 모세포분율 및 백혈구 수를 보인다고 한 이전 보고와 유사한 결과였다[1215]. 헤모글로빈은 $\mathrm{AML} \mathrm{MRC} \mathrm{환자에서} \mathrm{통계적으로} \mathrm{유의하지}$ 는 않지만 낮은 경향을 보여 최근 AML MRC 환자에서 $\mathrm{AML}$ NOS 환자에 비해 유의하게 낮은 헤모글로빈 수치를 보였다는 보고와 비슷하였다[18]. 또한 본 연구에서 AML MRC 환자가 AML NOS 환자에 비해 유의하게 낮은 FLT3 ITD 돌연변이, 유 의하게 짧은 전체생존기간, 무질병생존기간 및 낮은 완전관해 율을 보인 것은 최근 보고와 일치하였고[18], MRC 이외의 AML 환자와의 비교와 좋은 예후를 보이는 것으로 알려진 세포유전학 적 이상의 영향을 배제 후의 비교에서도 같은 결과를 보인 것은 AML MRC 환자에서 예후가 나쁜 것으로 알려져 있는 FLT3 ITD 돌연변이의 빈도가 낮았다는 것을 감안하였을 때 AML MRC 환자의 경우 그 자체만으로도 불량한 예후를 보임을 뒷받침하는 결과이다[1].

본 연구에서 $\mathrm{MRC}$ 로 정의된 세 군 간의 비교에서는 전체생존 기간 및 무질병생존기간 모두 유의한 차이가 없었는데 이는 이전 MDS 병력이 있었던 환자와 MLD가 있는 환자의 비교에서 생존 
기간의 차이가 없었다는 이전 보고와 일치한다[8]. 또한 $\mathrm{MLD}$ 를 동반한 $\mathrm{AML} \mathrm{MRC}$ 환자에서 $\mathrm{MDS}$ 연관 세포유전학적 이상을 보인 환자보다 유의하지는 않지만 낮은 완전관해율을 보인 것 과 이전 $\mathrm{MDS}$ 병력이 있었던 환자보다 높은 사망률을 보인 것, $\mathrm{MLD}$ 를 동반하지 않은 $\mathrm{AML}$ 환자에 비해 짧은 전체생존기간 및 무질병생존기간, 낮은 완전관해율, 높은 사망률을 보인 것, $\mathrm{AML}$ $\mathrm{NOS}$ 환자와의 비교에서도 무질병생존기간이 유의한 차이가 없 었던 것을 제외하고 같은 결과를 보인 것은 $\mathrm{MLD}$ 를 동반한 $\mathrm{AML}$ $\mathrm{MRC}$ 환자에서 $\mathrm{MLD}$ 를 동반하지 않은 $\mathrm{AML}$ 및 $\mathrm{AML} \mathrm{NOS} \mathrm{환}$ 자보다 낮은 생존율을 보였다는 이전 보고와 일치하였고 MLD의 존재가 불량한 예후인자임을 뒷받침하는 결과이다[8, 10]. 그러 나 좋은 예후를 보이는 세포유전학적 이상을 보인 환자군을 배 제 후의 비교에서는 낮은 완전관해율 및 높은 사망률을 보였지만 생존기간은 유의한 차이가 없었는데 이는 $\mathrm{MLD}$ 를 동반한 $\mathrm{AML}$ $\mathrm{MRC}$ 환자가 좋은 예후를 보이는 세포유전학적 이상을 제외한 $\mathrm{MLD}$ 이외의 $\mathrm{AML}$ 환자와 생존기간 및 무질병생존기간의 유의 한 차이가 없었던 이전 보고와 일치하여 $\mathrm{MLD}$ 의 예후인자로써 의 역할이 $\mathrm{MRC}$ 에 비해 모든 변수에서 일치하지는 않는다는 것 을 보여주는 결과이다[11].

여러 연구에서 실시한 임상적 변수들의 생존기간에 대한 다변 량분석에서 60 세 이상의 연령, 나쁜 예후를 보이는 세포유전학 적 이상은 공통적으로 나쁜 예후인자로 제시되고 있었으나 MLD 의 경우 예후인자로써 논란이 있었다. 본 연구에서는 60 세 이상 인 경우 전체생존기간 및 무질병생존기간, 완전관해율의 나쁜 예 후인자로 나타나 이전 보고들과 일치하였고 모세포분율이 $60 \%$ 이하인 경우 무질병생존기간의 나쁜 예후인자로 나타났으며 $\mathrm{MRC}$ 가 전체생존기간 및 무질병생존기간, 완전관해율의 나쁜 예후 인자로 나타났고 $\mathrm{MLD}$ 의 경우에도 $\mathrm{MRC}$ 와 같은 결과를 보였는 데 이는 $\mathrm{MRC}$ 및 $\mathrm{MLD}$ 를 나쁜 예후인자로 보고하였던 최근 보 고[18]와 일치하는 결과였으며 $\mathrm{MLD}$ 를 나쁜 예후인자로 인정하 지 않았던 이전 보고들과 상반된 결과였다[9-11]. 이는 비록 MLD 를 동반한 $\mathrm{AML} \mathrm{MRC} \mathrm{환자가} \mathrm{좋은} \mathrm{예후를} \mathrm{보이는} \mathrm{세포유전학적}$ 이상을 제외한 $\mathrm{MLD}$ 이외의 $\mathrm{AML}$ 환자와의 비교에서는 생존기 간의 유의한 차이가 없었지만 $\mathrm{MLD}$ 의 독립적인 예후인자로써 의 가능성을 제시해주는 결과이다.

결론적으로, 본 연구에서 $\mathrm{AML} \mathrm{MRC} \mathrm{환자가} \mathrm{AML} \mathrm{NOS} \mathrm{환자에}$ 비해 낮은 완전관해율과 짧은 전체생존기간 및 무질병생존기간을 보였고 $\mathrm{MLD}$ 를 동반한 $\mathrm{AML} \mathrm{MRC} \mathrm{환자도} \mathrm{유사한} \mathrm{결과를} \mathrm{보였으}$ 며 MLD를 동반하지 않은 $\mathrm{AML} \mathrm{MRC} \mathrm{환자와} \mathrm{비교하였을} \mathrm{때} \mathrm{예}$ 후의 차이가 없어 새로이 발생한 AML에서 $\mathrm{AML} M R C$ 중 MLD 의 존재가 독립적인 나쁜 예후인자가 될 수 있다고 사료된다.

\section{요 약}

배경 : 골수이형성관련 급성골수성백혈병(AML with myelodysplasia related changes, AML MRC)은 새로이 발생한 $\mathrm{AML}$ 에 비해 예후가 나쁘다는 것이 잘 알려져 있으나 $\mathrm{MRC}$ 중 다계열이형성(multilineage dysplasia, MLD)이 예후에 미치는 영향에 대해서는 논란이 있어 왔다. 이에 저자들은 $\mathrm{AML} \mathrm{MRC}$ 에서 $\mathrm{MLD}$ 의 예후적 의미에 대해 평가하였다.

방법 : 2001년 1월부터 2005년 12월까지 서울아산병원에서 $\mathrm{AML}$ 로 처음 진단받은 357 명의 환자들을 대상으로 하였다. 모든 환자들은 AML with recurrent genetic abnormalities (RGA), AML MRC, AML not otherwise specified (NOS)로 분류하 여 진단되었으며 전체생존기간, 무질병생존기간을 포함한 예후 인자들은 전자의무기록을 후향적으로 분석하여 얻었다.

결과 : $\mathrm{AML} \mathrm{MRC}$ 환자는 $\mathrm{AML} \mathrm{NOS} \mathrm{환자에} \mathrm{비해} \mathrm{완전관해}$ 율(44.7\% vs. $64.9 \%, P=0.002)$ 이 낮았고 전체생존기간(297일 vs. 561일, $P=0.004$ ) 및 무질병생존기간(229일 vs. 374일, $P=$ 0.004)이 짧았다. MLD를 동반한 AML MRC 환자도 AML NOS 환자에 비해 완전관해율(37.7\%, $P=0.001)$ 이 낮았고 전체생존 기간(351일, $P=0.036)$ 이 짧았으며 무질병생존기간(242일, $P=$ 0.076)도 짧은 경향을 보였다. 그러나 $\mathrm{MLD}$ 를 동반한 $\mathrm{AML} \mathrm{MRC}$ 환자와 $\mathrm{MLD}$ 를 동반하지 않은 $\mathrm{AML} \mathrm{MRC}$ 환자 간에는 생존기 간 및 완전관해율의 유의한 차이가 없었다.

결론 : $\mathrm{AML} \mathrm{MRC}$ 환자는 $\mathrm{AML} \mathrm{NOS} \mathrm{환자에} \mathrm{비해} \mathrm{완전관해}$ 율이 낮았고 전체생존기간 및 무질병생존기간이 짧았다. MLD 를 동반한 $\mathrm{AML} \mathrm{MRC} \mathrm{환자도} \mathrm{유사한} \mathrm{결과를} \mathrm{보였고} \mathrm{MLD}$ 를 동 반하지 않은 $\mathrm{AML} \mathrm{MRC} \mathrm{환자와} \mathrm{비교하였을} \mathrm{때} \mathrm{예후의} \mathrm{차이가}$ 없어 새로이 발생한 $\mathrm{AML}$ 에서 $\mathrm{AML} \mathrm{MRC} \mathrm{중} \mathrm{MLD}$ 의 존재가 독립적인 나쁜 예후인자가 될 수 있다고 사료된다.

\section{참고문헌}

1. Swerdlow SH, Campo E, et al. eds. WHO classification of tumours of hematopoietic and lymphoid tissues. 4th ed. Lyon: IARC Press, 2008.

2. Gahn B, Haase D, Unterhalt M, Drescher M, Schoch C, Fonatsch C, et al. De novo AML with dysplastic hematopoiesis: cytogenetic and prognostic significance. Leukemia 1996;10:946-51.

3. Cunningham I, Gee TS, Reich LM, Kempin SJ, Naval AN, Clarkson $\mathrm{BD}$. Acute promyelocytic leukemia: treatment results during a decade at Memorial Hospital. Blood 1989;73:1116-22. 
4. Sobol RE, Mick R, Royston I, Davey FR, Ellison RR, Newman R, et al. Clinical importance of myeloid antigen expression in adult acute lymphoblastic leukemia. N Engl J Med 1987;316:1111-7.

5. Yunis JJ, Brunning RD, Howe RB, Lobell M. High-resolution chromosomes as an independent prognostic indicator in adult acute nonlymphocytic leukemia. N Engl J Med 1984;311:812-8.

6. Gerhartz HH and Schmetzer H. Detection of minimal residual disease in acute myeloid leukemia. Leukemia 1990;4:508-16.

7. Jaffe ES, Harris NL, et al. eds. World Health Organization classification of tumours. Pathology and genetics of tumours of haematopoietic and lymphoid tissues. Lyon: IARC Press, 2001.

8. Arber DA, Stein AS, Carter NH, Ikle D, Forman SJ, Slovak ML. Prognostic impact of acute myeloid leukemia classification. Importance of detection of recurring cytogenetic abnormalities and multilineage dysplasia on survival. Am J Clin Pathol 2003;119:672-80.

9. Haferlach T, Schoch C, Loffler H, Gassmann W, Kern W, Schnittger $\mathrm{S}$, et al. Morphologic dysplasia in de novo acute myeloid leukemia (AML) is related to unfavorable cytogenetics but has no independent prognostic relevance under the conditions of intensive induction therapy: results of a multiparameter analysis from the German AML Cooperative Group studies. J Clin Oncol 2003;21:256-65.

10. Yanada M, Suzuki M, Kawashima K, Kiyoi H, Kinoshita T, Emi N, et al. Long-term outcomes for unselected patients with acute myeloid leukemia categorized according to the World Health Organization classification: a single-center experience. Eur J Haematol 2005;74: 418-23.

11. Wandt H, Schakel U, Kroschinsky F, Prange-Krex G, Mohr B, Thiede C, et al. MLD according to the WHO classification in AML has no correlation with age and no independent prognostic relevance as analyzed in 1766 patients. Blood 2008;111:1855-61.

12. Jinnai I, Tomonaga M, Kuriyama K, Matsuo T, Nonaka H, Amenomori $\mathrm{T}$, et al. Dysmegakaryocytopoiesis in acute leukaemias: its predominance in myelomonocytic (M4) leukaemia and implication for poor response to chemotherapy. Br J Haematol 1987;66:467-72.

13. Brito-Babapulle F, Catovsky D, Galton DA. Clinical and laboratory features of de novo acute myeloid leukaemia with trilineage myelodysplasia. Br J Haematol 1987;66:445-50.

14. Kuriyama K, Tomonaga M, Matsuo T, Kobayashi T, Miwa H, Shirakawa $\mathrm{S}$, et al. Poor response to intensive chemotherapy in de novo acute myeloid leukaemia with trilineage myelodysplasia. Japan Adult Leukaemia Study Group (JALSG). Br J Haematol 1994;86: 767-73.

15. Kim JM, Seo EJ, Park CJ, Chi HS. Significance of trilineage myelodysplasia in de novo acute myeloid leukemia. Korean J Clin Pathol 2000;20:442-8. (김지명, 서을주, 박찬정, 지현숙. 급성골수성백혈병에서 삼계열 이형성의 의의. 대한임상병리학회지 2000;20:442-8.)

16. Hoyle CF, Gray RG, Wheatley K, Swirsky D, de Bastos M, Sherrington $\mathrm{P}$, et al. Prognostic importance of Sudan Black positivity: a study of bone marrow slides from 1,386 patients with de novo acute myeloid leukaemia. Br J Haematol 1991;79:398-407.

17. Lima CS, Vassalo J, Lorand-Metze I, Bechelli AP, Souza CA. The significance of trilineage myelodysplasia in de novo acute myeloblastic leukemia: clinical and laboratory features. Haematologia (Budap) 1997;28:85-95.

18. Weinberg OK, Seetharam M, Ren L, Seo K, Ma L, Merker JD, et al. Clinical characterization of acute myeloid leukemia with myelodysplasia-related changes as defined by the 2008 WHO classification system. Blood 2009;113:1906-8.

19. Bao L, Wang X, Ryder J, Ji M, Chen Y, Chen H, et al. Prospective study of 174 de novo acute myelogenous leukemias according to the WHO classification: subtypes, cytogenetic features and FLT3 mutations. Eur J Haematol 2006;77:35-45.

20. Wakui M, Kuriyama K, Miyazaki Y, Hata T, Taniwaki M, Ohtake $\mathrm{S}$, et al. Diagnosis of acute myeloid leukemia according to the WHO classification in the Japan Adult Leukemia Study Group AML-97 protocol. Int J Hematol 2008;87:144-51. 